\title{
Gênero textual/discursivo como instrumento possibilitador de letramentos: práticas necessárias no contexto formal de ensino
}

\section{Apresentação}

Desde que o termo letramento apareceu no meio acadêmico, por volta dos anos 80, estudos têm apontado para a necessidade de um ensino que vise formar um sujeito capaz de interagir nas diferentes situações de uso da linguagem. Concomitante a isso, têm crescido as discussões sobre os diversos gêneros textuais/discursivos, os quais são essenciais ao agir humano. Considerando esse contexto, os artigos que compõem esse número temático têm como propósito ampliar as discussões sobre como o gênero textual/discursivo pode ser um instrumento possibilitador de letramentos ao mesmo tempo em que visa divulgar experiências exitosas que possam contribuir para uma educação de qualidade.

Nesse sentido, o artigo publicado postumamente "Práticas de Alto Impacto entre disciplinas: um estudo exploratório de um gênero pedagógico", escrito em Inglês por Flavia Renon, da Universidade de Carleton, Canadá, aborda a questão de letramentos acadêmicos investigando como práticas de alto impacto no nível universitário, assim definidas no Ensino Superior norte americano, são representadas no currículo. Renon mobiliza procedimentos swalesianos do Inglês para Fins Específicos (ESP) por meio da análise de movimentos retóricos e passos de um pequeno corpus de currículos com e sem práticas de algum impacto a fim de examinar como instrutores universitários organizam e comunicam sua compreensão das funções e propósitos de tais práticas. O estudo é concluído com a sugestão de que a análise de gênero da perspectiva do ESP tem papel importante no desenho curricular entre disciplinas e no treinamento de instrutores que elaboram currículos para cursos com práticas de alto impacto e de outros tipos.

"Solicitações em ambiente de trabalho: Uma resenha crítica da literatura", um artigo escrito em Inglês por Neil Lapierre da Universidade de Carleton, Canadá, aborda a questão de letramento em ambiente de trabalho, definido como a habilidade de usar tipos apropriados de texto em contextos de trabalho, por meio de uma resenha crítica da literatura que enfoca 
solicitações orais e por e-mail em ambiente de trabalho. Especificamente, o artigo lança luz sobre as solicitações de novos funcionários cuja língua primeira difere das línguas usadas no trabalho. Lapierre discute fundamentos teóricos de pesquisa publicada sobre solicitações em ambiente de trabalho, convenções e características de e-mail, e estratégias de requisição usadas no trabalho. $\mathrm{O}$ artigo identifica as diferenças principais entre os tipos de requisição oral e por e-mail no contexto laboral, e apresenta implicações para o letramento em ambiente de trabalho de novos empregados que falam outras línguas diferentes da língua dominante em seu contexto de trabalho.

Em seu artigo em Inglês, "Declarações de missão institucional: construção discursiva da identidade organizacional na educação pós-secundária Canadense", Sebin Jung, da Universidade de Carleton no Canadá, aborda a questão de altos níveis de letramentos esperados de futuros alunos que precisam navegar em sítios de instituições educacionais tais como faculdades e universidades, quando procuram por um futuro programa de estudo. Em particular, o artigo examina a construção discursiva da identidade organizacional em declarações de missão institucional de instituições pós-secundárias Canadenses selecionadas por meio da articulação da análise de movimentos retóricos e passos do ESP e de análise léxicogramatical, em um pequeno corpus de tais declarações. Os resultados do estudo indicam que apesar de comprometimentos/empenho servirem como um movimento obrigatório tanto em declarações de missão institucional de faculdades quanto de universidades, o empenho primário se difere entre eles refletindo, portanto, diferenças nos propósitos institucionais e funções desses dois tipos de instituições pós-secundárias. É sugerido que o ensino a futuros estudantes contemple a compreensão da natureza das declarações online de missão institucional para poder facilitar a escolha desses alunos de um programa adequado, vocacional ou acadêmico.

O artigo "Diálogo e interação na produção de textos na escola: análise de um evento de letramento", escrito por Maria do Socorro Alencar Nunes Macedo e Érica Feijó Lima, tem como propósito refletir sobre o trabalho com o letramento na escola considerando as práticas de trabalho com a produção de textos que foram realizadas com estudantes de um terceiro ano do ensino fundamental. Pautadas nos pressupostos dos novos estudos do letramento e na perspectiva enunciativa da linguagem proposta por Bakhtin, as autoras tecem uma análise a 
partir de uma das aulas ministradas por uma professora do Recife, em torno do gênero bilhete, que ocorreu mediante uma necessidade de comunicar os pais sobre uma reunião escolar. As análises refletem sobre a forma dialógica de intervenção da professora mediante uma situação de produção que não era prevista, mas que se tornou motivo de propiciar um ensino voltado para os eventos de letramento.

Adriana Cavalcanti dos Santos, Wilton Petrus dos Santos e Nádson Araújo dos Santos, no artigo intitulado "A produção textual em contextos do letramento e significação social", objetivam refletir sobre a produção escrita como prática de letramento e suas significações sociais considerando que o aprendizado acontece por meio das práticas dialógicas. Nesse sentido, os autores analisam uma experiência voltada para o trabalho com os gêneros do discurso da esfera publicitária, nas práticas de produção oferecidas no âmbito do PIBID, que se apoiou em uma proposta do livro didático pelo Programa Nacional do Livro e do Material Didático (PNLD) para os anos de 2017-2019 e que foi adotado pela escola participante.

Em "O texto visual no livro didático de língua portuguesa: reflexões e desafios em multimodalidade", Rafael Seixas de Amoêdo e Neiva Maria Machado Soares objetivam investigar de que forma o texto visual está sendo utilizado no livro didático Português Linguagens, de William Cereja e Thereza Magalhães. Dando ênfase à edição do 60 ano, por ser um material de fase transitória, os autores analisam se o texto visual, no respectivo material, tem uma natureza meramente ilustrativa ou se estimula o letramento visual/multimodal. Pautam-se, para isso, na Teoria Semiótica Social da Multimodalidade (TSSM) e na Gramática do Design Visual (GDV). A partir das análises realizadas, os autores chegam à conclusão de que há um relevante uso de ilustrações que exercem predominantemente uma função meramente acessória e que isso pode deturpar os critérios de coesão e coerência, quanto as perspectivas de multimodalidade, letramento visual e multiletramentos.

Cidinéia da Costa Luvison e Luzia Batista de Oliveira Silva, no artigo "Letramento matemático: um processo construído pelo narrar e pelas linguagens, apresentam uma experiência realizada em uma sala de 3 o ano do ensino fundamental com o intuito de discutir sobre o letramento em aulas de matemática, a partir do uso das linguagens enquanto parte do desenvolvimento conceitual pelo aluno. Pautando-se na perspectiva histórico-cultural e enunciativo-discursiva, as autoras selecionam algumas narrativas orais e escritas realizadas 
pelos alunos de uma escola pública municipal do interior de São Paulo para análise. Ressaltam, por meio delas, que o letramento está aliado às práticas sociais e que se torna possível a partir de uma intencionalidade no ato pedagógico, em busca de levar o aluno a se comunicar, ler, narrar e transformar-se.

Em "Um estudo sobre o gênero digital HQtrônica em Língua Inglesa”, Luana Fossatti Testa, Siderlene Muniz-Oliveira, Didiê Ana Ceni Denardi procuram analisar o gênero digital HQtrônica, construindo um modelo didático para posterior elaboração e aplicação de sequências didáticas. Pautando-se nas considerações do interacionismo sociodiscursivo, analisam a situação de produção, os mecanismos textuais - de textualização e enunciativos, bem como os processos multimodais e ressemióticos do episódio 1 da série da HQtrônica Batman: Legends of The Dark Knight, o qual tem como título: "The Butler Did It". Ressaltam que a partir do modelo didático apresentado, é possível aos professores a construção de sequências didáticas que auxiliem os alunos no desenvolvimento de capacidades de linguagem do respectivo gênero, bem como da leitura em língua inglesa.

Claudia de Jesus Abreu Feitoza e Milena Moretto, no texto "O trabalho com gêneros textuais em um curso de Pedagogia: uma proposta de produção editorial para o letramento profissional" objetivam discutir acerca das contribuições de uma experiência prática de formação inicial no que diz respeito à aprendizagem de leitura e escrita de diversos gêneros textuais que $-m$ embora não pertençam à esfera acadêmica - serão objeto de ensino dos pedagogos em atuação nos diferentes segmentos de ensino e anos em que irão atuar. Pautando-se na perspectiva enunciativo-discursiva e nas considerações dos Novos Estudos do Letramento, analisam algumas produções de texto que foram realizadas por alunos do 5 o semestre de Pedagogia e que compuseram um projeto editorial que era a proposta de trabalho final da disciplina Fundamentos e Metodologias do Ensino de Língua Portuguesa. As autoras ressaltam, a partir da análise dos textos, que essa prática possibilitou, antes de se tornarem objetos de ensino dos futuros professores pedagogos, a apropriação das especificidades desses gêneros por eles.

Em "Ensino interdisciplinar da escrita de resenhas na educação profissional", Sandra Costa Lima, Samuel de Carvalho Lima e José Araújo Amaral analisam uma experiência desenvolvida em um Curso Técnico de Nível Médio em Edificações na modalidade de Educação 


\section{HSF HORIZON TES}

de Jovens e Adultos, em que os conteúdos das disciplinas de Língua Portuguesa e Biologia foram integrados e promoveram a escrita de resenhas de uma obra audiovisual, cujo tema era meio ambiente. Nesse texto, os autores discutem sobre a intervenção pedagógica realizada e a prática de letramento por meio de um questionário que foi aplicado a sete alunos participantes. Ressaltam, após as análises, que os dados evidenciam que os estudantes obtiveram um desenvolvimento em relação às especificidades da resenha e uma boa compreensão sobre a poluição e o papel do consumo.

O artigo de Cristovão e Vignoli, "Ações de Didatização de Gêneros em prol de Letramentos Acadêmicos: práticas e demandas", expõe as características gerais de um projeto de pesquisa com três fases. Nesse texto, as autoras apresentam os procedimentos voltados para o primeiro objetivo que é mapear as demandas e expectativas por atividades e ações de letramentos acadêmicos em três Instituições de Ensino Superior públicas paranaenses. Com o resultado do mapeamento, o projeto entrará em sua segunda fase que é a proposição de ações didáticas conjuntas nas universidades envolvidas em um processo de implementação do Laboratório Integrado de Letramentos Acadêmicos - LILA. As pesquisadoras discutem também as dificuldades implicadas no processo e alternativas de superação.

Esperamos que a leitura dos artigos que compõem este dossiê possa trazer reflexões profícuas a respeito de diferentes práticas de leitura e escrita tendo em vista os estudos do letramento, provocar (trans)formações, bem como suscitar e dialogar com novas pesquisas que ainda estão por vir.

Milena Moretto (USF)

Cleide Inês Wittke (UFPEL)

Vera Lúcia Lopes Cristovão (UEL)

Natasha Artemeva (Carleton University)

Organizadoras 